\title{
我国某些铅锌矿床的硅、氧 同位素地球化学研究
}

\author{
蒋少通 丁梯平 万德芳 \\ (中国地质科学院矿林地质研究所, 北京 100037)
}

\section{关筑调硅同位素、硅质来源、铅锌矿林}

碂是组成矿床岩石和矿物的最主要元素之一, 应用硅同位素来研究矿床问题、示踪物质来 源、解决矿床成因是很有潜力和希望的. 但至今为止国内外这方面的研究未见报道. 因为硅 同位索组成自然变化小, 分析测试精度要求高, 研究难度大. 尽管国外从 50 年代起就有人开 始探索硅同位素，几十年来仅对陨石、月岩和某些地球岩石和矿物作过一些初步的硅同位素分 析,积累了硅同位素组成自然变化的基础资料 ${ }^{[1,2]}$. 但缺乏进一步深人的研究. 1988 年, 我们 在国内首次建立了硅同位索测量装置和方法，对国外的方法作了改进，测量精度大大提高 ${ }^{[3]}$. 最近两年来，作者对我国华北地台北缘的一些大型铅锌矿床进行了硅同位素分析. 结合司 位索研究试图来示踪物质来源、原岩饭复和解决矿床成因上的某些问题. 从所获数据结果看, 效果比较理想. 为矿床同位索地质研究开辟了一个重要的新研究方向.

\section{一、矿床地质特征简介}

本文主要研究了华北地台北缘元古宙铅锌成矿带中炭窑口、东升庙、甲生盘、八家子、青城 子和关门山等大型铅锌矿床. 它们均产在元古宙的泥质岩一细碎屑岩-碳酸盐岩建造内, 并限 定在一些元古代的裂陷海槽内的次级盆地中. 矿带内矿床的层控特征明显, 矿体主要成层产 出, 呈层纹状、条带状或透镜状. 其中一些受后期地质改造作用强烈的矿床(如青城子)、或主 要是热液改造作用成矿的矿床 (如关门山、八家子), 则出现脉状矿化和一些形态不规则的矿 体. 矿床的矿物组成比较简单, 金属矿物以黄铁矿、方铅矿、闪锌矿、黄铜矿和磁黄铁矿为主, 脉石矿物主要是白云石、方解石、石英、云母和绿泥石等. 赋矿地层遭受了程度不等的区域变 质作用. 在青城子地区变质程度最高, 达绿窝角闪岩一角闪岩相. 炭窑口、东开庙和甲生盘矿 区为绿片岩相. 关门山和八家子矿区基本未变质. 与成矿有关的花岗岩将活动仅见于八家子 和青城子矿区. 更详细的地质情况可参见文献 [4].

\section{二、同位素分析方法}

样品的硅同位素分析采用 $\mathrm{BrF}$ ，法, 将样品中的硅转化为 $\mathrm{SiF}_{4}$ 气体, 用蒸馏纯化法使 $\mathrm{SiF}_{4}$ 与 $\mathrm{BrF}_{5}$ 等其他杂质气体反复分离, 纯化后的 $\mathrm{SiF}_{4}$ 再通过加热到 $70^{\circ} \mathrm{C}$ 的装有锌粒的 铜管进一步除去掺杂在 $\mathrm{SiF}_{4}$ 中的极微量活性氧化物气体杂质. 获得的超纯净 $\mathrm{SiF}_{4}$ 气体用 
MAT-251 EM 恝宅体质谱计测量其硅同位素组成. 测量结果用 $8^{30} \mathrm{Si}$ 表示:

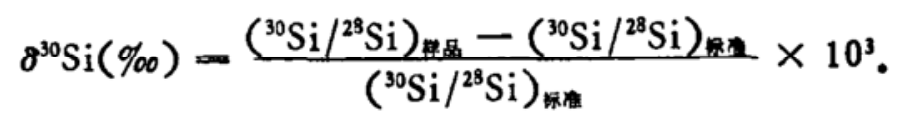

采用的标准为美国国家标准局的 NBS-28 石英砂标样. 样品的分析测量精度小于 $\pm 0.1 \%$ 。

氧同位素分析是按 Clayton 等所描述的传统 $\mathrm{BrF}_{5}$ 法进行 ${ }^{[9]}$, 用 MAT-251EM 质谱测 量,分析精度为 $\pm 0.2 \%$ 。分析过程中, 一般对同一份样品同时进行硅和氧同位素分析.

\section{三、分析结果与讨论}

所有样品的硅、氧同位素分析结果均列于表 1 中.

炭窑口、东升庙矿区三个石英岩样品 $\delta^{30} \mathrm{Si}$ 为 $0--0.2$, 与我们已检测的碎屑沉积石英砂 岩的 $8^{30} \mathrm{Si}$ 特征值一致. 它们的 $8^{18} \mathrm{O}$ 为 $11.5-14.2$, 两个 $\delta^{13} \mathrm{O}$ 值稍高的样品可能反映岩石 中有部分自生石英的形成. 这些石英岩的原岩是碎屑沉积的石英砂岩.

上述两个矿床和甲生盘矿床地层中硅质条带和燧石层的 $\delta^{3 j} \mathrm{Si}$ 值明显分为两组: 一组接 近零值 $(-0.1-0.2)$; 另一组稍正 $(0.6-0.8)$. 前者主要产于细碎屑岩中, 而后者产于混灰岩 中,它们的 $8^{30} \mathrm{Si}$ 值的不同也许反映了其硅质来源或沉淀方式的不同,但我们还无法进一步论 证. 它们的 $8^{18} \mathrm{O}$ 值均比石英岩的高(19.8-21.2), 显示化学或生物化学沉积的特征. 三个矿 区均发育各种各样的石英脉, 主要有两种类型:（1）产于片岩层中, 延深较长的石英脉或方 解石石英脉; (2) 产于矿层中的含硫化物短小石英脉或石英团斑. 第一类石英脉一个样品的 $8^{30} \mathrm{Si}$ 为 $-0.2,8^{18} \mathrm{O}$ 为 11.5 . 第二类石英脉五个样品的 $\delta^{30} \mathrm{Si}$ 为 $-0.2-0, \delta^{18} \mathrm{O}$ 为 $17.9-20.6$; 一个样品 $\delta^{30} \mathrm{Si}$ 为 $0.5,8^{18} \mathrm{O}$. 为 21.9. 从这些结果可以得出两点认识:

(1) 第二类石英脉的 $8^{30} \mathrm{Si}$ 值与地层中硅质条带和燧石层相类似地分为两组, 数值也吻 合. 说明形成这些石英脉的硅质具有就地取材特征, 它们是经变质或热液原地改造或重结晶 形成的.

（2）第一类石英的 $8^{18} \mathrm{O}$ 值低, 可能反映其形成时外来溶液(主要是地下雨水)的影响. 第 二类石英 $\delta^{18} \mathrm{O}$ 值高, 并与地层中硅质条带和遂石层的值一致, 它们是在水岩比很小的情况下 由层间水改造原有地层形成的, 在炭窑口和东升庙变质程度比甲生盘稍高, 因此石英的 $8^{18} \mathrm{O}$ 值比甲生盘的稍低。

在炭窑口, 测定了三号矿体中一个黑云母 $8^{30} \mathrm{Si}$ 为一 $0.2,8^{18} \mathrm{O}$ 为 $7.8 ;$ 一个绿泥石化黑云 母 $8^{30} \mathrm{Si}$ 为 $-0.5, \delta^{18} \mathrm{O}$ 为 4.2. 可以看出两个样品的硅、氧同位素具有同步变化的趋势. 蚀 变过程中样品的 $\delta^{30} \mathrm{Si}$ 组成稍有降低.

在东升庙, 测定了五号矿体中一条含云母石英黄铁矿脉, 黑云 $8^{30} \mathrm{Si}$ 为 $-0.4,8^{18} \mathrm{O}$ 为 11.5 ; 金云母的 $8^{30} \mathrm{Si}$ 为 $-0.2, \delta^{18} \mathrm{O}$ 为 12.0 ; 石英的 $\delta^{30} \mathrm{Si}$ 为 $0,8^{18} \mathrm{O}$ 为 18.0 . 三个样品的 硅、氧同位素也具有同步变化的趋势.

青城子矿床, 矿体中石英与变质石英脉的 $8^{18} \mathrm{O}$ 值明显不同,前者为 $11.7-13.7$, 后者为 16.0. 但它们的 $8^{30} \mathrm{Si}$ 值相同, 并与含矿地层岩石斜长角闪片岩、硅化大理岩的 $8^{30} \mathrm{Si}$ 值一致, 三者均为 $-0.2-0.1$. 因此, 无论是变质石英脉还是矿体中石英, 其硅质来源均是就地取材, 即来自地层本身. 对变质地层中石榴石、黑云母和金云母的 $8^{30} \mathrm{Si}$ 和 $8^{18} \mathrm{O}$ 分析表明, 片岩中 石榴石 $8^{30} \mathrm{Si}$ 为 $-1.1--0.9,8^{18} \mathrm{O}$ 为 12.9 ; 黑云母 $8^{30} \mathrm{Si}$ 为 $-0.6--1.3,8^{18} \mathrm{O}$ 为 9.4-11.3. 而云母条带大理岩中金云母的 $8^{30} \mathrm{Si}$ 为 $0.9,8^{18} \mathrm{O}$ 为 12.0 . 这些数据说明形成片岩中黑云母 
表 1 样品的 $8^{30} \mathrm{Si}$ 和 800 测定值

\begin{tabular}{|c|c|c|c|c|}
\hline 样昂 & 样品名称 & $8^{80} \mathrm{Si}\left(\%_{0}\right)$ & $8^{11} O(\%)$ & 样品采策地点上状 \\
\hline TDB-8 & 石英岩 & 0 & 11.5 & 掞晏口,地层中 \\
\hline T-7 & 同上 & -0.1 & 14.2 & 同上 \\
\hline D-5 & 同上 & -0.2 & 14.2 & 东升庙,地层中 \\
\hline$T-34 *$ & 磷石层 & 0.2 & & 苂密口,铜矿体中夹层 \\
\hline J104 - 20 & 硅质条带 & -0.1 & 19.8 & 甲生盘, 羒础质板岩中 \\
\hline $\mathrm{J} 304-13$ & 同上 & 0.6 & 21.2 & 甲生盘,泥灰岩中 \\
\hline J94- I & 同上 & 0.8 & & 甲生盘,萠灰岩中 \\
\hline TDB-14 & 石英 & -0.2 & 11.5 & 炭密口,绿泥石片岩中石英脉 \\
\hline TDB-24 & 石英 & -0.2 & 19.0 & 决密口,三号矿体石英黄铁矿石 \\
\hline D.7 & 石莫 & -0.1 & 17.9 & 东升庙，五号矿体黄铁矿石英脉 \\
\hline D-14 & 石英 & 0 & 18.0 & 东升庙，五号矿体含云母黄铁矿石莫脉 \\
\hline $\mathrm{J} 304-7$ & 石英 & -0.1 & 20.1 & 甲生盘,1 号矿体黄铁矿石英脉 \\
\hline J104- 12 & 石英 & -0.1 & 20.6 & 甲生盘，1 号矿体黄铁矿石英䐂 \\
\hline J2-6 & 石英 & 0.5 & 21.9 & 甲生盘, II 号矿体下进石英脉 \\
\hline TDB-17 & 绿泥石化黑云母 & -0.5 & 4.2 & 炭密口,三号矿体黄编矿石 \\
\hline TDB-20 & 黑云母 & -0.2 & 7.8 & 炭密口,三号矿体黄铜矿石 \\
\hline D-14-1 & 黑云母 & -0.4 & 11.5 & 东开庙，五号矿体含云母费铁矿石莫脉 \\
\hline D-14-2 & 金云母 & -0.2 & 12.0 & 东开庙，五甼矿体含云母黄铁矿石英肤 \\
\hline QD-18 & 石英 & -0.2 & 13.7 & 城子,320 号矿体中 \\
\hline QZ-23 & 石英 & -0.1 & 11.7 & 肖城于,289 告矿体中 \\
\hline QD-11 & 石莫 & -0.1 & 16.0 & 昔城子,变质石英脉 \\
\hline QD-1* & 科长角以片岩 & -0.1 & & 需城子,2 号矿体下盘国岩 \\
\hline QZ-10* & 硅化大理岩 & -0.1 & & 青城子,320 号矿体下盘国岩 \\
\hline QZ-24* & 硅化大理岩 & -0.2 & & 青城子,289号矿体下盘国岩 \\
\hline 85D29-1 & 石稫石 & -0.9 & 12.9 & 青城子,石榴石云母片岩 \\
\hline $86 Z-1$ & 石籍石 & -1.1 & 12.9 & 春城于, 石畄石云母片岩 \\
\hline 85D29-2 & 黑云母 & -0.6 & 9.4 & 青城石, 石榴石云母片岩 \\
\hline $86 \times L-1$ & 黑云母 & -0.3 & 10.9 & 䛔城子,石榴石云母片岩 \\
\hline $85 \mathrm{D}-\mathrm{B}$ & 黒云母 & -0.4 & 11.0 & 青城子, 石樆石云母片岩 \\
\hline $85 N-14$ & 黑云母 & -0.4 & 11.3 & 青城子,云母片岩 \\
\hline $85 N-10$ & 金云母 & 0.9 & 12.0 & 青城子，云母条肃大理岩 \\
\hline $8-16$ & 石英 & -0.1 & 11.2 & 八家于,石英队长岩 \\
\hline $8-16$ & 黑云母 & -0.3 & 5.6 & 八家于,石英以长岩 \\
\hline $8-12$ & 细云母 & 0.1 & 8.8 & 八家子 黄铁㶲英岩 \\
\hline $8 \mathrm{~N}-2$ & 石英 & 0.1 & 12.5 & 八家子,块状黄铁矿石中 \\
\hline $8 \mathrm{~N}-3$ & 蛇纹石 & 0.7 & 3.7 & 八家子,白云岩裂隐中 \\
\hline BH-9 & 逐内石 & 1.5 & 10.8 & 八家子，冓石条带附近运以石化 \\
\hline $8-28$ & 星石条带 & 2.8 & 18.8 & 八家子,白云岩层中 \\
\hline $8 \mathbf{N}$ & 肈石条带 & 1.7 & 11.0 & 八家子,白云岩层中 \\
\hline $8 \mathrm{H}-8$ & 䂣石余带 & 1.7 & 17.4 & 八家子,白云岩层中 \\
\hline GX-9 & 石英 & 0.3 & 22: & 关门山,白云岩中白色石英脉 \\
\hline$G X-1-2$ & 石英 & 0.4 & 23.3 & 关门山,块状铅锌矿石中 \\
\hline
\end{tabular}

- 样品经过化学处理,提纯出 $\mathrm{SiO}_{2}$.

和石榴石的硅质与形成条带大理岩中金云母的硅质来源是明显不同的. 进一步的分析表明 ${ }^{D}$, 片岩中黑云母和石榴石是由风化成因的高岭石粘土矿物变质而成或者与当时的海底火山喷气

1）蒋少涌等,中国她质科学院院报,1991. 
物质有一定关系. 形成金云母的硅质则可能是就地取材的大理岩层中璔石条带。

八家子矿床, 石英闪长岩中石英的 $\delta^{30} \mathrm{Si}$ 为 $-0.1, \delta^{18} \mathrm{O}$ 为 11.2 ;黑云母的 $8^{30} \mathrm{Si}$ 为 -03 . 近接触带黄铁绢英岩中绢云母的 $8^{30} \mathrm{Si}$ 为 0.1 , 块状黄铁矿石中石英的 $\delta^{50} \mathrm{Si}$ 为 $0.1, \delta^{18} \mathrm{O}$ 为 12.5. 离接触带稍远的蚀变矿物蛇纹石 $8^{30} \mathrm{Si}$ 为 0.7 , 透闪石的 $8^{30} \mathrm{Si}$ 为 1.5. 地层中煫石条带 的 $8^{33} \mathrm{Si}$ 为 $1.7-2.8, \delta^{14} \mathrm{O}$ 为 $11.0-18.8$. 可以看出, 成矿热液中硅质来源在接触带附近是以 岩将源为主, 而远离接触带则地层煫石硅的贡献很大.

关门山矿床只测定了一个地层中白色石英脉的 $8^{30} \mathrm{Si}$ 为 $0.3,8^{18} \mathrm{O}$ 为 22.5 ; 一个块状铅㻭 矿石中石英的 $8^{30} \mathrm{Si}$ 为 $0.4, \delta^{19} \mathrm{O}$ 为 23.3. 这些数据说明它们的硅质来源是源自地层的.

总之,利用矿床中石英及其他含硅矿物的硅同位素组成分析, 可以有效地判别硅的来源, 为解决矿床成因问题提供依据. 这是一个具有广阔前景的研究领域.

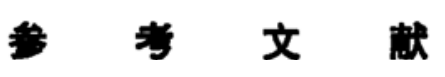

[1] Douthitt, C. B., Geoch. et Cosmoch. Acta, 8(1982),1449-1457.

[2] Clayton, R. N., Review in Mineralogy, 1986, 129-139.

[3] 丁悌平等, 矿床地质, $4(1988), 90-96$.

[4]蒋少涌等, 矿产与勘查, 3(1990), 1一7.

[5] Clayton, R. N. and Mayeda, T. K., Geoch. et Cosmoch. Acta, 27(1963),43-52. 